\title{
On the Possible Function of Telfairia occidentalis Agglutinin in the Plant
}

\author{
R. A. Togun,* O. Otusanya ${ }^{\dagger}$ and A. Aboderin $*$ \\ Department of Haematology and Immunology Obafemi Awolowo University, Ile-Ife, Nigeria \\ 'Department of Botany, Obafemi Awolowo University, Ile-Ife, Nigeria \\ ${ }^{ \pm}$Department of Biochemistry, University of Uyo, Uyo, Nigeria
}

Received 7 April 2004, Accepted 7 July 2004

\begin{abstract}
The fate of Telfairia occidentalis seed Agglutinin, TOA, has been monitored during germination. While the level of the Agglutinin in the cotyledons decreased sharply in the first three days to about half of the initial level, it stabilises at this level for the following twelve days. In this interval, Agglutinin activity becomes manifest in the radicle on the fourth day, peaking on the fifth and decreasing rapidly thereafter. In the plumule, the lectin activity becomes manifest on the sixth day, peaks on the seventh and decreases rapidly thereafter. No lectin activity is detectable in any plant tissue including the rump of the cotyledons twenty-seven days after germination. The implications of these observations on the possible role of lectins in plants are discussed.
\end{abstract}

Keywords: Plant Lectins, Seed Germination, Telfairia occidentalis Agglutinin

\section{Introduction}

Lectins are carbohydrate-binding proteins that agglutinate red blood cells and are ubiquitous in plants, animals and microbes (Sharon and Goldstein, 1998). A wide variety of biological functions are mediated by lectin-carbohydrate interactions. These include agglutination, the capability to serve as recognition molecules with a cell, between cells, or between organisms (Chrispeels and Raikhel, 1991); adhesion, cancer metastasis, bacterial and viral infections, inflammation and cellular growth (Varki, 1993).

Plant lectins have widespread use as biomedical reagents and they are assumed to play fundamental biological roles in plants because they are found in many different species and in many different organs and tissues. Mitogenic plant lectins can stimulate the transformation of cells from the resting phase to blast formation and proliferation. These mitogens have been employed to study the probable role of lectins in cell growth and development (Ashraf and Khan, 2003). Their use has led to an increased understanding of the relationship between chromosomal abnormality and human diseases, which has helped in diagnosis.

In view of these important functions plant lectins have been extensively studied. Proposed biological functions of plant lectins include symbiotic recognition (Van Rhijn et al., 1998) seed storage (Goldberg et al., 1989) defence against predators and pathogens (Chrispeels and Raikhel, 1991) growth regulation (Howard et al., 1972) role in embryogenesis, vegetative and reproductive development (Brill et al., 2001). However, in spite of all the efforts, the functions of plant lectins have remained enigmatic (Chrispeels and Raikhel, 1991; Sharon and Goldstein, 1998; Brill et al., 2001; Rudiger and Gabius, 2001).

One of the intriguing facts about the soluble proteins in the seed of Telfairia occidentalis is that a strongly mitogenic agglutinin, Telfairia occidentalis Agglutinin (TOA) accounts for a good one third of total extractable protein (Togun et al., 1994a). This is much higher than what appears to be the case for other well-known seeds, which are sources of agglutinins of various specificities, such as Caesalpinia bonduc (Ajomale et al., 1997), Dioclea reflexa (Adeyemi et al., 1994) and Tetracarpidium conophorum (Togun et al., 1994b) for which a figure of $5-10 \%$ is typical.

We seek in this study to identify possible function(s) of TOA during the germinative process by monitoring the levels of the lectin at various stages both in the diminishing cotyledon and in the newly formed plant tissues: roots, stem and leaves.

*To whom correspondence should be addressed.

Tel: 2348034058622

E-mail: ttogun@yahoo.com 


\section{Materials and Methods}

The seeds used in this study were collected from a matured pod of Telfairia occidentalis plant stand in the campus Obafemi Awolowo University, Ile-Ife, Nigeria, during the fruiting season. The seeds were extracted from the fruit pod, and washed thoroughly to remove surrounding matrical tissue. The seeds to be planted were selected on the basis of uniformity in size.

Growing procedure Large plastic bowls were punched at several points at the bottom and filled to two-third levels with humus soil. The holes were to facilitate effective drainage. Four seeds were sown at well-spaced points just below soil surface levels and watering was done on a daily basis until the experiment was completed. The pots were kept in an open space where they were exposed to sunlight and other natural conditions. Two seeds that were not planted represented the Day 0 samples.

Two samples (seeds or plants) were harvested everyday starting from the day after the planting, i.e. day 1, for analysis. As from when germination of seeds started and thereafter, the lengths of the plumule and radicle were measured. Using a sharp scalpel, each plant was separated into its different components- radicle, plumule and cotyledon or, later, cotyledon, root, stem, leaves, petioles and tendrils. Each component was ground and extracted independently of the others.

Preparation of crude extracts Dried seeds (Day 0) as well as swollen seeds and different parts of germinating plants were ground in five volumes of phosphate buffered saline $(0.15 \mathrm{M}$ sodium

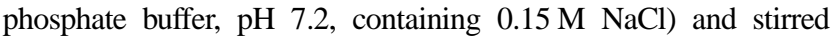
overnight at $4^{\circ} \mathrm{C}$. Each suspension was centrifuged at $3000 \mathrm{rpm}$ at room temperature and the resultant supernatant was stored frozen until required.

Haemagglutination assay Haemagglutination activity of extracts of seeds and different parts of germinating seedlings and plants was determined as earlier described (Togun et al., 1994a).

Haemagglutination experiments were performed in V-shaped microtitre plates. Lectin preparation $(0.1 \mathrm{ml})$ was serially diluted in doubling dilutions in the wells of the microtitre plates with phosphate buffered saline ( $\mathrm{pH}$ 7.2). This process was carried out for two complete rows (or 24 wells) for each sample. Human red blood cell suspension $(2 \%)$ previously fixed with glutaraldehyde $(1 \% \mathrm{v} / \mathrm{v})$ was added to each of the wells in $0.1 \mathrm{ml}$ aliquots. The plates were incubated at room temperature for 2-24 hours to allow for the agglutination of erythrocytes to take place. The titre of the lectin was taken as the reciprocal of the last dilution showing agglutination of erythrocytes.

Protein concentration determination Protein concentrations were measured according to a modification of the Lowry technique (Lowry et al., 1951).

\section{Results}

A general description of stage-by-stage and day-to-day morphological changes in the structure of planted seeds of Telfairia occidentalis up to seventeen days of germination is summarised in Table 1. Figures 1 and 2 respectively summarise the fate of the lectin content in the cotyledon and the radicle/ root and the plumule/shoot.

Changes in the levels of the specific activity of TOA in the cotyledon appear to take place in three phases (Fig. 1). A rapid drop in specific activity to about one half of the initial value by the end of the third day is followed over the next twelve days during which the level of activity was relatively unchanged. After this, the activity decreased progressively and was barely detectable in the rump of the cotyledon by the 27 th day. Neither the tendrils, which appeared on the 18th day, nor the by-now well-developed root, stem and leaves had any detectable lectin activity.

The radicle was visible within the split cotyledon by the third day of planting with a very high content of lectin (titre of $2^{7}$ ). The titre increased on day 4 , when the shoot had not yet appeared. With the emergence of the plumule rudiments on day 5 , the root lectin activity drastically dropped to a titre of $2^{2}$, and totally disappeared by day 7 , when the root had been properly formed, with branches.

Similarly, the shoot first appeared as plumule rudiments on day 5 with a high content of lectin activity (titre of $2^{6}$ ), which decreased rapidly to a titre of $2^{3}$ on day 6 as the rudiments began to differentiate into leaves. As the shoot matured and developed matured leaves, lectin activity continued to diminish until it completely disappeared on day 13 , by which time a fully grown shoot with a woody stem and non succulent leaves was in place.

\section{Discussion}

Our data show that TOA lectin activity peaks at the earliest stages of emergence of the different tissues (root and shoot), and disappears as soon as the tissues are properly established. Given the physical continuity between cotyledons, the epicotyl and the hypocotyl via the cotyledonary node, we ascribe the lectin activity in the developing plant parts to activity derived from the seed during the first phase referred to above (Fig. 1) and not as a result of a de novo synthesis, either in the radicle or plumule. This finding suggests that the protein may be involved in stimulating, as a mitogen, the multiplication of the cells of the tissue to be developed only to disappear once the differentiation of the tissue cells has taken place. This interpretation is consistent with our earlier observations on the mitogenicity of TOA, which is comparable to that displayed by Concanavalin A and PHA (Togun et al., 1994a). It is also supported by the observations of Brill et al. (2001), who, using genetic engineering techniques to analyze the functions of lectin genes, concluded that the gene products are not only important for embryogenesis, but are also required throughout plant development. 
Table 1. Germination of T. occidentalis Seed

\begin{tabular}{|c|c|c|c|c|}
\hline Day & Specimen & $\begin{array}{l}\text { Length } \\
(\mathrm{cm})\end{array}$ & Weight $(\mathrm{g})$ & Description of growth state \\
\hline 0 & Whole seed & - & 6.7 & Unsplit whole seed \\
\hline 1 & Whole seed & - & 8.8 & Carp (husk) slightly split \\
\hline 2 & Whole seed & - & 8 & Same as above. Cotyledon chlorophyllous \\
\hline \multirow{2}{*}{3} & Cotyledon & - & 10 & Split cotyledon. \\
\hline & Radicle & 1.6 & 0.1 & Emergence of main Radicle \\
\hline \multirow{2}{*}{4} & Cotyledon & - & 9.8 & Cotyledons more widely separated. \\
\hline & Radicle & 5.3 & 0.3 & Radicle growth more pronounced. \\
\hline \multirow{3}{*}{5} & Cotyledon & - & 12.2 & Cotyledons almost completely separated. \\
\hline & Radicle & 5.5 & 0.4 & Branch roots appearing. \\
\hline & Plumule & 1.5 & 0.1 & Plumule rudiments present. \\
\hline \multirow{3}{*}{6} & Cotyledon & - & 11 & Cotyledons separated. \\
\hline & Radicle & 7.2 & 0.2 & More root branches forming. \\
\hline & Plumule & 1.6 & 0.1 & Plumule forms rudiments of leaf structure. \\
\hline \multirow{3}{*}{7} & Cotyledon & - & 14.2 & Cotyledons chlorophyllous \\
\hline & Radicle & 8.5 & 0.7 & Same as Day 5. \\
\hline & Plumule & 3.6 & 0.4 & Shoot well differentiated, chlorophyllous, almost emerging out of separated cotyledons. \\
\hline \multirow{3}{*}{8} & Cotyledon & - & 12.7 & Cotyledons separated, except at the point of joining to the young seedling. \\
\hline & Radicle & 10.4 & 0.6 & Several long branch roots, some as long as the taproot. \\
\hline & Plumule & 7 & 1.2 & Thick succulent herbaceous stem. Two fully formed leaves, others in an apical fold. \\
\hline \multirow{3}{*}{9} & Cotyledon & - & 12.4 & Same as Day 8 \\
\hline & Radicle & 12.6 & 1 & Several branch roots, some longer than the taproot. \\
\hline & Plumule & 9.6 & 2.1 & Tall shoot. Three leaves open, others in a fold. \\
\hline \multirow{3}{*}{10} & Cotyledon & - & 14.4 & Same as Day 8 \\
\hline & Radicle & 17.5 & 1.5 & Several branch roots, some longer than the taproot. \\
\hline & Plumule & 12 & 3.1 & $\begin{array}{l}\text { Stem thickens, becoming woody at the basal part. Well-developed leaves. } \\
\text { Alternate leaf branching. }\end{array}$ \\
\hline \multirow{3}{*}{11} & Cotyledon & - & 13.2 & Same as Day 8 \\
\hline & Radicle & 13.2 & 1.5 & Roots continue to grow bigger with many fully-grown branches. \\
\hline & Plumule & 13.3 & 3.9 & $\begin{array}{l}\text { Two base leaves opening up at shoot base. Stem base becoming woody. } \\
\text { Leaves less succulent. }\end{array}$ \\
\hline \multirow{3}{*}{13} & Cotyledon & - & 12.1 & Same as Day 8 \\
\hline & Radicle & 14 & 1.2 & Roots fully developed but still growing longer. \\
\hline & Plumule & 20.3 & 7.4 & Trifoliate or quadrifoliate leaves fully developed. Long petioles. \\
\hline \multirow{3}{*}{14} & Cotyledon & - & 14.3 & Shrinking cotyledon. Leathery, no longer succulent. \\
\hline & Radicle & 16.2 & 2.1 & Same as above. Root diameter increasing at base. \\
\hline & Plumule & 40 & 13.5 & $\begin{array}{l}\text { Base leaves fully grown and also forming petioles. Leaves no longer succulent. } \\
\text { Shoot becoming woody. }\end{array}$ \\
\hline \multirow{3}{*}{15} & Cotyledon & - & 15.6 & Same as Day 14 \\
\hline & Radicle & 15.4 & 2.6 & Root diameter continues to expand at base. Many branches. \\
\hline & Plumule & 36.5 & 14.6 & Mature leaves toughens, not succulent. \\
\hline 17 & & ND & ND & Shoot has become woody. \\
\hline 18 & & ND & ND & Appearance of tendrils \\
\hline
\end{tabular}




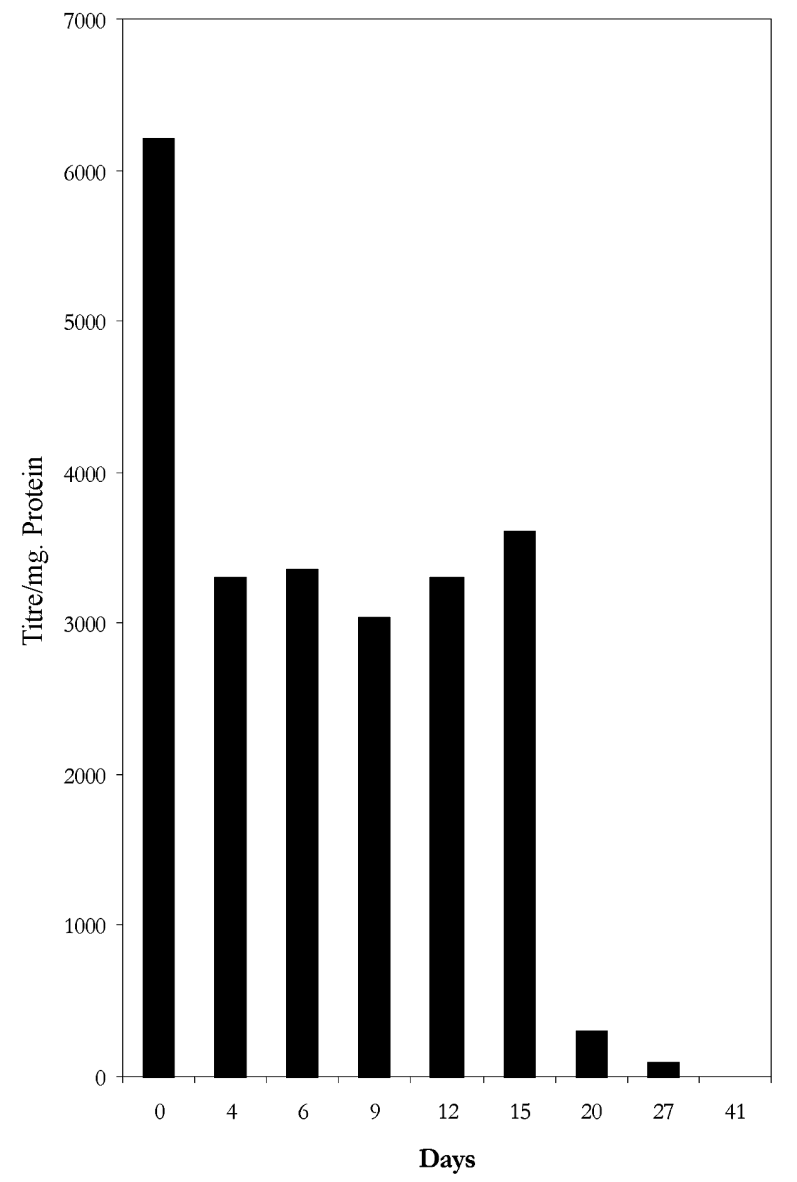

Fig. 1. Changes in the level of the specific activity of TOA in the fresh seed and in the cotyledon of the germinating seed of Telfairia occidentalis Agglutinin (TOA) during seed germination. Agglutination Titre values and protein concentration were estimated as described by Togun et al., 1994a and Lowry et al., 1951, respectively.

It is instructive to compare some of the observations described above with the results obtained by Martinez-Cruz et al. (2001), from their studies on the lectin from corn (Zea mays) coleoptiles, which had the highest specific activity at the 7 th day after seeding. In spite of the fact that $T$. occidentalis and Zea mays belong in two different classes, the functional lectin in each case is Galactoside-binding while the activity during germination peaked, in each case, on the seventh day.

The fact that TOA activity disappeared in the shoot, stem and leaves and essentially completely in the rump of the cotyledons by the 15th day of seed planting and would not be present in the mature plant only after seed formation argues in favour of the position that the agglutinin is not required throughout plant development. Although no direct information has been adduced in this work on the matter, it appears unlikely that the agglutinin is present for plant defensive purposes as suggested by Peuman and Van Damme (1995) and by Martinez-Cruz et al., (2001) who

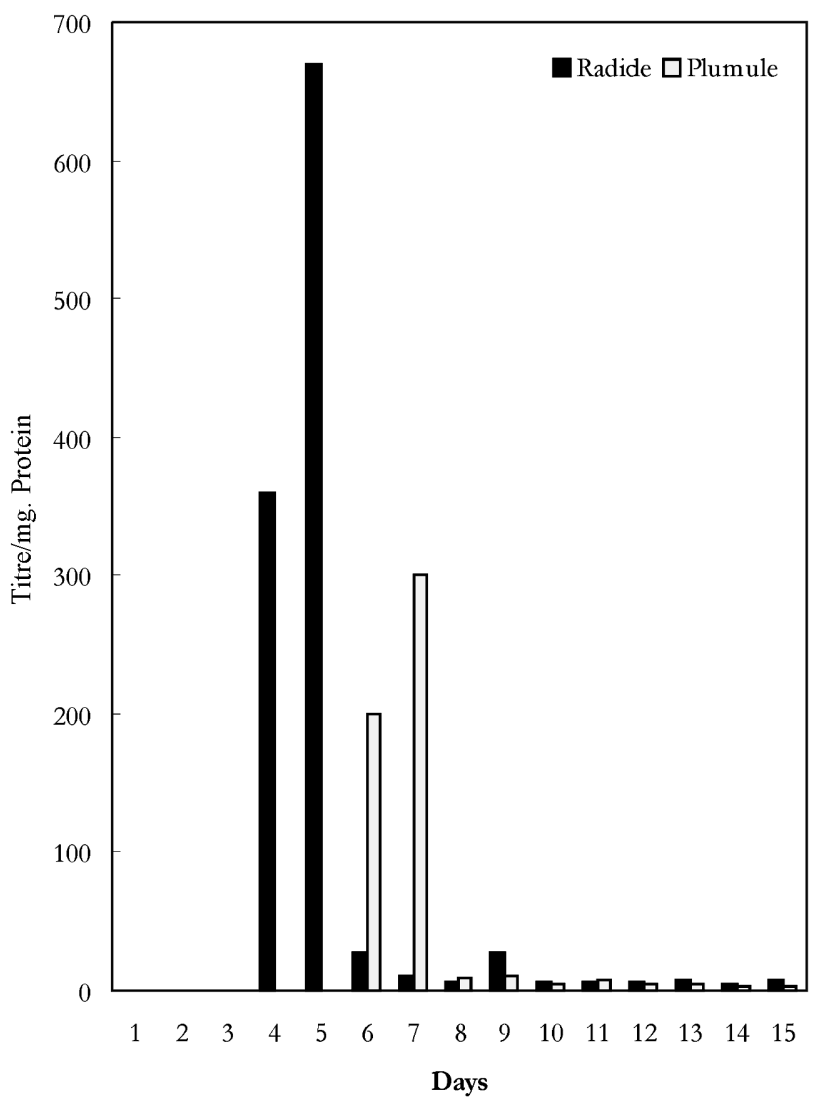

Fig. 2. Specific Activity of TOA in the Radicle (Black bars) and Plumule (White bars) during the germination of $T$. occidentalis seeds. Agglutination Titre values as well as protein concentration determinations were as described in Fig. 1.

have proposed specific interactions with rhizobial components or microorganisms.

\section{Conclusion}

The data presented in this study suggest one definite role for Telfairia occidentalis seed lectin during germination: that of the stimulation of the multiplication of the tissues to be differentiated. This is to be expected of a lectin that is a mitogen and from the manner and sequence of its appearance in the developing root and shoot. It is doubtful, however, if this can be the sole biological function of the lectin, given the large amount of it that is present in the mature seed (see Introduction) and the small fraction of it that was required during germination (Figs. 1 and 2). Additional work will be required to uncover other roles, if any.

\section{References}

Adeyemi, A., Togun, R. A., Ogunbiyi, O. A. and Aboderin, A. (1994) Observations on the Haemagglutinins from the Seeds of 
Dioclea reflexa (Hook) Nigerian J. Biochem. 9, 26-36.

Ajomale, K., Binutu, O. O., Togun, R. A. and Aboderin, A. (1997) A Galactose-binding Lectin from the Seeds of Caesalpinia bonduc (Linn.) Roxb. (Caesalpiniaceae) Nigerian J. Biochem. Mol. Biol. 13, 23-28.

Ashraf, M. T. and Khan, R. H. (2003) Mitogenic Lectins. Med. Sci. Monit. 9, 265-269.

Brill, L. M., Evans, C. J. and Hirsch, A. M. (2001) Expression of MsLEC 1- and MsLEC 2- antisense genes in alfalfa plant lines causes severe embryonic developmental and reproductive abnormalities. Plant J. 25, 453-461.

Butler, W. T. (1963) Haemagglutination studies with formalinised erythrocytes. J. Immunol. (Baltimore) 90, 663-671.

Chrispeels, M. J. and Raikhel, N. V. (1991) Lectins, lectin genes, and their role in plant defense. Plant Cell 3, 1-9.

Howard, I. K., Sage, H. J. and Horton, C. B. (1972) Studies on the location of haemagglutinins from a common lentil during the life cycle of the plant. Arch. Biochem. Biophys. 149, 323326.

Lowry, O. H, Rosebrough, N. J., Farr, A. L. and Randall, R. J. (1951) Protein measurement with the Folin Phenol reagent. $J$. Biol. Chem. (Baltimore) 193, 265-275.
Martinez-Cruz, M., Zenteno E. and Cordoba, F. (2001) Purification and characterization of a galactose-specific lectin from corn (Zea mays) coleoptile. Biochim. Biophys. Acta 1568, 37-44.

Peumans, W. J. and Van Damme, E. J. (1995) The role of lectins in plant defence. Histochem. J. 27, 253-271.

Rudiger, H. and Gabius, H. (2001). Plant lectins: occurrence, biochemistry, functions and applications. Glycoconjugate J. 18, 589-613.

Sharon, N. and Goldstein, I. J. (1998) Lectins: more than insecticides. Science 282, 1049.

Togun, R. A., Animashaun, T., Kay, J. E. and Aboderin, A. (1994a) A Galactose-binding mitogenic lectin from the seeds of Telfairia occidentalis. Phytochemistry 35, 1125-1130.

Togun, R. A., Binutu, O. O., Animashaun, T. and Aboderin, A. (1994b) $\beta$-Galactoside lectins from the seeds of Tetracarpidium conophorum. Nigerian J. Biochem. 9, 17-25.

Van Rhijn, P., Goldberg, R. B. and Hirsch, A. M. (1998) Lotus corniculatus nodulation specificity is changed by the presence of a soybean lectin gene. Plant Cell 10, 1233-1250.

Varki, A. (1993) Biological roles of oligosaccharides: all of these theories are correct. Glycobiology 3, 97-130. 